\title{
Interactive comment on "Using Satellite-Based Evapotranspiration Estimates to Improve the Structure of a Simple Conceptual Rainfall-Runoff Model" by Tirthankar Roy et al.
}

Tirthankar Roy et al.

royt@email.arizona.edu

Received and published: 18 October 2016

We thank Mr. Tso for his valuable comments on our manuscript and nicely pointing out what we should do when we have new sources of information available.

Regarding his specific comments:

[1] We agree that the word 'ideal' is probably not the best choice here. We are now using the word 'appropriate' instead of 'ideal'.

Printer-friendly version

[2] We are now using consistent symbol for the correlation coefficient.
Discussion paper

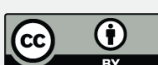

